They were divided into three equal groups, one receiving 2,000 IU daily, another 10,000 IU daily, and the third 50,000 IU daily. The patients were treated for up to one year and the number of fits occurring during this time compared with the number recorded during a similar period immediately before vitamin $\mathrm{D}$ treatment. The results are presented in the table. A breakdown of the results into treatment groups did not reveal a dose-related effect.

Effect of Vitamin D Therapy on Fit Frequency in 21 Patients (Maior fits = with convulsions; minor fits = all other types).

\begin{tabular}{c|c|c|c}
\hline \multirow{2}{*}{$\begin{array}{c}\text { Type of } \\
\text { Fit }\end{array}$} & \multicolumn{2}{|c}{ Fit Frequency } \\
\cline { 2 - 4 } \cline { 3 - 4 } & Reduced & Unchanged & Increased \\
\hline Major $\ldots$ & 6 & 7 & 8 \\
\hline Minor .. & 11 & 3 & 7 \\
\hline
\end{tabular}

Despite the duration of treatment and the size of the doses given to the patients no increase in the mean plasma calcium level of the 21 patients was seen $(8.9 \mathrm{mg} / 100 \mathrm{ml}$ before and at the end of the treatment period), which is in accord with the findings of Dr. Christiansen and his colleagues. Contrary to their experience, however, all but two of our patients showed a fall in plasma alkaline phosphatase (mean values 10.4 K.A. units before treatment and 8.3 K.A. units after)

We did not find these results sufficiently encouraging to justify proceeding to a placebo-controlled study.-We are, etc.,

St. Bartholomew's Hospital,
London E.C.1

ALAN RICHENS

King's College Hospital Dental School,

DAvid J. F. ROWE 1 Richens, A., and Rowe, D. J. F., British Medical

1970, 4, 69., et al., British Medical fournal,
Dent,

\section{Postpartum Tubal Ligation and Local} Anaesthesia

SIR,-The importance of adequate anaesthetic cover in maternity hospitals has constantly been emphasized to avoid the accidents referred to in the Report on Confidential Enquiries into Maternal Deaths 1 and to deal with the increaring demand for epidural analgesia. Until the anaesthetic services expand to meet these requirements it is difficult to demonstrate any priority for a general anaesthetic for the routine postpartum tubal ligation which occurs at short notice.

To overcome this problem a method of performing tubal ligation under local anaesthesia within 24-48 hours of delivery has been introduced in this hosvital. The patient is prepared for the vessibility of a general anaesthetic, and premedication with $100 \mathrm{mg}$ of pethidine intramuscularly is given 30 minutes before operation. Immediately before scrubbine up diazepam is given intravenously$10 \mathrm{me}$ at first and more added during operation if necessarv. Local infiltration is carried cut with
$20 \mathrm{ml}$ of $1 \%$ prilocaine hydrochloride and a routine $20 \mathrm{ml}$ of $1 \%$ prilocaine hvdrochloride and a routine
Pomerov operation performed using plain catqut.

Of 208 patients in the initial study, three required a general anaesthetic, two because they were uncooperative in spite of additional diazepam and local anaesthetic and one because of adhesions. The remainder cooperated well and there were no respiratory difficulties, though often a total of $20 \mathrm{mg}$ diazepam was required. The patients found the degree of sedation and amnesia acceptable and the postoperative sequelae were less than after general anaesthesia.

Our impressions stimulated a prospective study, and a preliminary assessment of this shows the method to be so acceptable to staff and patients that we feel it could be the method of choice even if general anaesthesia was more readily available.-We are, etc.,

ALOKa Dey Maternity Hospital, South Shields GORDON MACKAY 1 Department of Health and Social Security, Report
on Confidential Enquiries into Maternal Deaths
in England and Wales, 1967-1969. London,
H.M.S.O., 1972.

\section{Malaria in the United Kingdom}

SIR,-In their article on this subject Professor L. J. Bruce-Chwatt and others (29 June, p. 707) conclude that "protection from malaria infection when travelling ... is to a large extent the responsibility of the individual concerned. The medical profession can only advise the public at large and organizations concerned with overseas travel of the risk of infection."

I would like to know where, when, and how the "individuals concerned" (who will number over a million this year, according to the authors) are expected to get the necessary information about protection. The ordinary traveller hardly ever approaches a practitioner before he goes abroad, and, unless things have considerably improved recently, he is unlikely to get much help even if he does. (Maybe the recent issue to all practitioners by the Department of Health and Social Security of the pamphlet referred to below mav have had some useful effect.)

The only people the traveller usually sees about his journey if he is going by air, as $95 \%$ do, are the agent, the airport authorities, and the representatives of the carriers, including the cabin staff. The agents and the carriers do not seem to go out of their way at the moment to offer health advice to the traveller who may be going on some glamorous package tour to the malarious tropics. International regulations regarding smallpox, yellow fever, and cholera are carried out, as they have to be, but there the matter often ends. The excellent pamphlet "Notice to Travellers-Health Protection" (Health Departments and Central Office of Information) is supposed to be iscued to all travel agents. Unfortunatelv there is no official pressure on the agent, as there should be, to offer a copy of the pamphlet or to disclose its contents to the potential traveller.

It is time the public was pioperly protected from its dangerous ignorance of the sometimes serious health hazards of travel abmar by making cure that the information available reaches them. As I see it, the maior respnnsibility for this must rest with the arant and the carrier. Of course it is ultimatelv "the responcibility of the individual concerned" to swallow the antimalarial tahlets that he should have been told about. The same is true of using a life jacket and swimming if the plane falls in the sea. In the airnraft the public are warned by the public address system. Why not warn them about malaria?
The medical profession should be more positive than merely offering advice. It should go out of its way to influence the press, television, and the other media which spend so much of their time cajoling the innocent (and, in my view, unprotected) public to take a holiday "in the sun," which could easily mean exposure to potentially dangerous diseases such as malaria. To put the onus for protection against malaria on "the individual concerned" seems to me to be completely unrealistic in present circumstances.-I am, etc.,

BRIAN MAEGRAITH

Liverpool School of Tropical Medicine,

Liverpool

\section{Vein Stripping}

SIR, -Dr. D. Freedman's arguments on vein stripping (18 May, p. 387) provoke some comments.

(1) It is not fair to quote the report by Galen in 150 A.D. (or, even worse, the operative report on the diotator Marius much earlier) as an argument against vein stripping. Firstly, the operative technique was very different from modern stripping. Secondly, Dr. Freedman may have heard of something called anaesthesia and proper postoperative treatment, including analgesics, anti-inflammatory drugs, and good bandaging, which certainly make the postoperative period something very far from "mediaeval torture."

(2) It is correct that stripping does not take care of the incompetent perforators. It should be kept in mind, however, that varicose veins and incompetent perforators are not synonymous. They are two different states with different symptoms. If both are present at the same time measures should be taken against both, which is easily dome at the same operation.

(3) Stripping from the ankle to the groin is possible in one stage in about $80 \%$ of cases of even very tortuous varicose veins. If not possible further incisions along the saphenous pathway are easily done without further harm to the patient or the surgeon. It it absolutely not true that "only normal veins can be stripped."

(4) In our series of 5,400 ambulant strippings the risk of postoperative complications was below $2 \%$, even very slight inf ctions and postoperative bleeding included. We had onlv three more serious complications $(0.06 \%)$ none of which threatened life or limb. It is true that arterial complications were reported in the literarure. In Sweden, however, six such cases were reported to the Medical Board. It was found that all these operations were done by inexperienced surgeons. It is unfair to judge a surgical method by the results obtained by surgeons unfamiliar with the basic techniaue of the operation.

(5) The long saphenous vein may be used as a spare part for reconstructive arterial surgery in very few cases. It should be remembered (a) that there is another saphenous vein; $(b)$ that most strippings are performed on women and the mainrity of arterial reconstructions on men; $(c)$ that many methods, such as, for example, endarterectomy, are available; and $(d)$ that it is a doubtful medical principle to abstain from the best possible treatment for the reason that the patient in the future might develop another disease. 